\title{
Parental smoking increases exhaled nitric oxide in young children
}

\author{
P.J. Franklin*, S. Turner*,\# ${ }^{*}$ R. Mutch ${ }^{\top}$ and S.M. Stick*,\#
}

\begin{abstract}
The present study investigated the association between reported parental smoking and exhaled nitric oxide fraction $(\mathrm{FeNO})$ in young children.

In total, 78 children (24 females, mean age 51.3 weeks) were recruited. Fourteen lived with one smoking parent and eight with two smoking parents. FeNO was measured using the modified single-breath technique.

Mean \pm SD FeNO levels were $33.0 \pm 18.9,38.3 \pm 15.0$ and $48.3 \pm 14.7 \mathrm{ppb}$ for children with no, one and two smoking parents, respectively. There was a significant linear trend across the groups and, after controlling for other relevant factors, a significant difference between the groups.

In the present study, exposure to environmental tobacco smoke was associated with increased exhaled nitric oxide fraction in young children. Furthermore, there was evidence of a doseresponse relationship between childhood exhaled nitric oxide fraction and the number of smoking parents.
\end{abstract}

KEYWORDS: Children, exhaled nitric oxide, passive smoking

E xhaled nitric oxide (exhaled nitric oxide fraction; $F \mathrm{eNO}$ ) appears to reflect allergic airway inflammation [1]. It may also be a biomarker for the acute respiratory effects of exposure to airway irritants [2] and is raised as a result of exposure to a range of ambient, domestic and occupational pollutants [3-5]. Environmental tobacco smoke (ETS) is an important airway irritant; however, the effect of ETS on FeNO in children is unclear.

Active smoking is associated with reduced $F$ eNO [6]. Controlled exposure to ETS can also decrease levels [7, 8]; however, in most epidemiological studies, no effect of passive smoke exposure on FeNO has been observed [9-11]. The situation is less clear in infants where parental smoking may either decrease [12,13] or increase [13] tidal FeNO, with the relationship being dependent on maternal atopy. As part of a study of lung function and airway inflammation in young children, the current authors investigated the relationship between reported parental smoking and FeNO in this age group.

\section{METHODS}

\section{Subjects and protocol}

The results from 78 children ( 24 females, mean age 51.3 weeks (range 13-106 weeks)), who had FeNO data and had been well for at least 2 weeks before testing, were included in the present study. Thirty-six children had a history of wheeze. All children underwent pulmonary function testing that included measures of lung volumes (forced expiratory volume in 0.5 seconds (FEV0.5)) and FeNO. Children were studied in the supine position, asleep following an oral dose of chloral hydrate $\left(60-100 \mathrm{mg} \cdot \mathrm{kg}^{-1}\right)$. FeNO was measured using the single-breath technique, as described previously [14]. The expiratory flow was $11 \mathrm{~mL} \cdot \mathrm{s}^{-1}$. FEV0.5 was measured using the raised-volume, rapid thoraco-abdominal compression technique [15]. FeNO was always measured first. The study was approved by the Medical Ethics Committee of the Princess Margaret Hospital for Children and written informed consent was obtained from the parents.

\section{Statistical analyses}

FeNO was normally distributed. FEV 0.5 values were converted to a z-score $(\mathrm{FEV} z)$, using data collected previously [16], and were also normally distributed. Parental smoking was categorised both as a binomial variable (yes/no) and by the number of smokers (none/one/both). The effect of parental smoking on both FeNO and FEVz was analysed using unpaired t-tests and ANOVA. A dose-response relationship between the number of smoking parents $(0,1$ or 2$)$ and FeNO was determined using the Chi-squared test for linear trend. Multiple linear regression was used to examine the association between paternal smoking and FeNO adjusted for the child's age, sex, health status (history of wheeze versus no history of wheeze), doctor-diagnosed eczema and FEVz,
AFFILIATIONS

*School of Paediatrics and Child Health, University of Western Australia,

\# Dept of Respiratory Medicine, Princess Margaret Hospital for Children, and

"TVW Telethon Institute for Child Health Research, Perth, Australia.

CORRESPONDENCE

P.J. Franklin

School of Paediatrics and Child Health

University of Western Australia GP0 Box D184

Perth 6840

Western Australia

Fax: 61893882097

E-mail: peterf@sph.uwa.edu.au

Received:

January 172006

Accepted after revision:

June 092006

\section{SUPPORT STATEMENT}

The study was supported by a grant from the National Health and Medical Research Foundation (NHMRC). P. Franklin and S. Stick are supported by NHMRC Fellowships. The nitric oxide analyser (Sievers NOA 280; Sievers Instruments Inc, Boulder, CO, USA) was purchased with an untied research grant from GlaxoSmithKline, Australia. 
as well as maternal atopy. Maternal atopy was defined as at least one positive reaction to a skin prick test. Finally, given previous findings in infants [13], a multiple linear regression model was constructed to assess whether maternal atopy modified the relationship between parental smoking and FeNO. This model included the two main effects (parental smoking and maternal atopy) and an interaction term (maternal atopy $\times$ parental smoking). Data are expressed as mean \pm SD.

\section{RESULTS}

Twenty-two children lived with at least one smoker. Of these, 14 lived with one smoking parent and eight with two smoking parents. Fathers (13 out of 14 ) were the main smokers in oneparent-smoking households. There were no differences in age, height, weight, $\mathrm{FEV} z$, proportion of wheezers, doctor-diagnosed eczema and maternal atopy between children from smoking and nonsmoking households (table 1).

Children who had at least one smoking parent had higher FeNO than children in nonsmoking homes $(\mathrm{p}=0.052)$. Mean \pm SD FeNO values for the two groups were $41.9 \pm 15.3$ and $33.0 \pm 18.9 \mathrm{ppb}$, respectively. Within the smoking group, FeNO was $38.3 \pm 15.0$ and $48.3 \pm 14.7 \mathrm{ppb}$ for those with one and two smoking parents, respectively (fig. 1; table 1). The difference between the three groups was not significant $(p=0.07)$, but there was a significant dose-response relationship across the three groups $(p=0.023)$. In the linear regression model, parental smoking significantly increased FeNO after controlling for other factors in both the two- $(9.4 \mathrm{ppb} ; 95 \%$ confidence interval (CI) $0.4-17.7 \mathrm{ppb}$ in smoking group, $\mathrm{p}=0.041$ ) and three-group analyses (table 1). In the three-group analysis, children with two smoking parents had significantly greater

\begin{tabular}{lccc} 
TABLE 1 & $\begin{array}{c}\text { Anthropometric, lung function and exhaled nitric } \\
\text { oxide fraction (FeNO) data for children grouped } \\
\text { according to the number of smoking parents }\end{array}$ \\
& \multicolumn{4}{c}{ Number of smoking parents } \\
\cline { 2 - 4 } & $\mathbf{0}$ & $\mathbf{1}$ & $\mathbf{2}$ \\
\hline & 56 & 14 & 8 \\
Subjects & $38 / 18$ & $9 / 5$ & $7 / 1$ \\
Sex M/F & $48.9 \pm 24.6$ & $53.3 \pm 19.6$ & $64.6 \pm 13.2$ \\
Age weeks & $74.2 \pm 6.5$ & $74.9 \pm 5.5$ & $78.7 \pm 4.6$ \\
Height cm & $9.9 \pm 1.9$ & $10.3 \pm 1.6$ & $10.9 \pm 2.3$ \\
Weight kg & $30 / 26$ & $7 / 7$ & $5 / 3$ \\
Hx wheeze yes/no & $24 / 29$ & $5 / 9$ & $2 / 6$ \\
Maternal atopy yes/no & $40 / 16$ & $8 / 6$ & $4 / 4$ \\
Eczema yes/no & $-0.07 \pm 1.1$ & $0.01 \pm 0.9$ & $-0.54 \pm 1.1$ \\
FEVz & & $3.4(-7.0-13.7)$ & $16.6(2.9-30.4)$ \\
FeNo ppb\# & \multicolumn{3}{c}{}
\end{tabular}

All continuous data are expressed as $n$ or mean $\pm S D$, unless otherwise indicated. M: male; F: female. ${ }^{\#}$ : Difference (95\% confidence interval) in FeNO compared with children of nonsmoking parents after controlling for child's age, sex, health status (history of wheeze $(\mathrm{Hx})$ versus no $\mathrm{Hx}$ ), doctor-diagnosed eczema, values of forced expiratory volume in 0.5 seconds converted to a zscore $(\mathrm{FEV} z)$, and maternal atopy. Children with two smoking parents had significantly greater $F$ eNO than children with no smoking parents $(p=0.014)$ and there was a significant linear trend across the three groups $(p=0.007)$



FIGURE 1. Exhaled nitric oxide fraction $(F \mathrm{eNO})$ for children grouped by the number of smoking parents. __ : mean (unadjusted); $\square$ : children with a history of wheeze; $\bigcirc$ : nonwheezers.

FeNO than children in nonsmoking homes $(+16.6 \mathrm{ppb} ; 95 \% \mathrm{CI}$ 2.9-30.4, $\mathrm{p}=0.019)$. Age, sex, maternal atopy, doctor-diagnosed eczema and $\mathrm{FEV}_{\mathrm{z}}$ were not associated with FeNO. FEVz was also not associated with parental smoking. Finally, there was no significant interaction between maternal atopy and parental smoking on FeNO $(\mathrm{p}=0.19)$.

\section{DISCUSSION}

In the present study, parental smoking was associated with an increase in FeNO in young children. Furthermore, there was evidence of a dose-response relationship between FeNO and the number of smoking parents. Increased FeNO has previously been reported in infants of smoking atopic mothers [13], whereas it is low in healthy newborns of smoking nonatopic mothers $[12,13]$. This suggests that the presence of maternal atopy modifies the relationship between maternal smoking and $F$ eNO in young children. In the present study, there was no significant interaction between maternal atopy and parental smoking on FeNO; however, there was insufficient power to adequately investigate such an interaction.

Raised FeNO observed in the present study, as well as in infants of smoking atopic mothers reported elsewhere [13], is interesting as cigarette smoke has mostly been associated with lower FeNO. FeNO is decreased in smokers [6] and can also be reduced immediately after smoking a cigarette [6, 7], although CHAMBERs et al. [17] reported a short-term increase in FeNO directly after smoking a cigarette. Cigarette smoke has been shown to decrease inducible nitric oxide synthase (iNOS) in vitro [18].

The effect of ETS on FeNO is less clear. In controlled exposure studies, passive smoking can cause an acute decrease in FeNO in nonsmoking healthy subjects [7, 8]. Most epidemiological studies have not found an effect of parental smoking on FeNO in children [9-11], although WARKE et al. [19] reported lower FeNO in exposed compared with unexposed asthmatic children. Most of these studies have used reported parental smoking as the exposure variable. This may not always be a 
good indicator of exposure for older children [20]. However, reported smoking may be a good marker of exposure for young children as they are generally unable to remove themselves from the source. Indeed, Le SEOUF et al. [21] found a strong relationship between reported parental smoking and urinary cotinine levels in infants, but only a weak relationship, which decreased with age, in children $>2$ yrs of age.

The mechanism for increased FeNO in very young children exposed to ETS is not known. It is possible that it may be an early marker of allergic sensitisation. $F$ eNO is strongly associated with atopy in children, even in the absence of disease [9], and there is evidence that pre-natal and early life exposure to ETS increases the risk of allergic sensitisation in young children $[22,23]$, although the data are not consistent [24]. Another explanation is that FeNO reflects the acute irritant effects of exposure to ETS in this age group [13].

There was evidence of a dose-response relationship between the number of smoking parents and FeNO in children. This has not been reported previously; however, as numbers of children with two smoking parents in the present study are small $(n=8)$, this finding should be treated cautiously. It was not possible to determine whether this was due to increased exposure from having two smoking parents or from maternal smoking alone, as all but one of the one-smoking-parent smokers were fathers. Future studies should include an objective marker of ETS exposure, such as urinary cotinine, to better determine exposure levels. Interestingly, urinary cotinine levels are reported to be highest in infants living with two smoking parents, although levels are still significantly higher in infants with smoking mothers only compared with those with smoking fathers only [25].

FREY et al. [13] found that both pre- and post-natal smoking were, separately, associated with increased FeNO. In the present study, it was not possible to differentiate between the effects of pre- and post-natal ETS exposure, as only one of the smoking mothers did not smoke during pregnancy.

In the present study, FeNO was measured using a single-breath technique [14]. FREY et al. [13] measured infant FeNO during tidal breathing and also found an association with parental smoking. There is no standard method for collecting FeNO in very young children, although some measure of flow needs to be considered $[13,26]$. The consistency of the results, despite different collection methods, suggests that these may not be just chance findings.

In an earlier paper on FeNO in the same cohort, the present authors reported that levels were significantly higher in females than males. After a small increase in subject numbers, this association was not evident in the current analyses. In a Swiss study [13], infant males had higher FeNO than females, but only in the offspring of mothers with atopic disease. Maternal atopy had no influence on sex differences in FeNO in the present study (data not shown).

In the present study, parental smoking was associated with increased exhaled nitric oxide fraction in children with evidence of a dose-response relationship. The mechanisms for this are unknown. Potential mechanisms and issues, such as the separate effects of pre- and post-natal environmental tobacco smoke exposure and the influence of maternal atopy on the association between parental smoking and exhaled nitric oxide fraction, should be explored further.

\section{ACKNOWLEDGEMENTS}

The authors would like to thank all children and their parents for participating in the study, and E. Pascoe for statistical advice.

\section{REFERENCES}

1 Payne DN. Nitric oxide in allergic airway inflammation. Curr Opin Allergy Clin Immunol 2003; 3: 133-137.

2 van Amsterdam JG, Nierkens S, Vos SG, Opperhuizen A, van Loveren $H$, Steerenberg PA. Exhaled nitric oxide: a novel biomarker of adverse respiratory health effects in epidemiological studies. Arch Environ Health 2000; 55: 418-423.

3 Franklin P, Dingle P, Stick S. Raised exhaled nitric oxide in healthy children is associated with domestic formaldehyde levels. Am J Respir Crit Care Med 2000; 161: 1757-1759.

4 Steerenberg PA, Nierkens S, Fischer PH, et al. Trafficrelated air pollution affects peak expiratory flow, exhaled nitric oxide, and inflammatory nasal markers. Arch Environ Health 2001; 56: 167-174.

5 Maniscalco M, Grieco L, Galdi A, Lundberg JO, Sofia M. Increase in exhaled nitric oxide in shoe and leather workers at the end of the work-shift. Occup Med (Lond) 2004; 54: 404-407.

6 Kharitonov SA, Robbins RA, Yates D, Keatings V, Barnes PJ. Acute and chronic effects of cigarette smoking on exhaled nitric oxide. Am J Respir Crit Care Med 1995; 152: 609-612.

7 Yates DH, Breen H, Thomas PS. Passive smoke inhalation decreases exhaled nitric oxide in normal subjects. Am J Respir Crit Care Med 2001; 164: 1043-1046.

8 Maniscalco M, Di Mauro V, Farinaro E, Carratu L, Sofia M. Transient decrease of exhaled nitric oxide after acute exposure to passive smoke in healthy subjects. Arch Environ Health 2002; 57: 437-440.

9 Franklin PJ, Taplin R, Stick SM. A community study of exhaled nitric oxide in healthy children. Am J Respir Crit Care Med 1999; 159: 69-73.

10 Barreto M, Villa MP, Martella S, et al. Exhaled nitric oxide in asthmatic and non-asthmatic children: influence of type of allergen sensitization and exposure to tobacco smoke. Pediatr Allergy Immunol 2001; 12: 247-256.

11 Dinakar C, Lapuente M, Barnes C, Garg U. Real-life environmental tobacco exposure does not affect exhaled nitric oxide levels in asthmatic children. J Asthma 2005; 42: 113-118.

12 Hall GL, Reinmann B, Wildhaber JH, Frey U. Tidal exhaled nitric oxide in healthy, unsedated newborn infants with prenatal tobacco exposure. J Appl Physiol 2002; 92: 59-66.

13 Frey U, Kuehni C, Roiha H, et al. Maternal atopic disease modifies effects of prenatal risk factors on exhaled nitric oxide in infants. Am J Respir Crit Care Med 2004; 170: 260-265.

14 Franklin PJ, Turner SW, Mutch RC, Stick SM. Comparison of single-breath and tidal breathing exhaled nitric oxide levels in infants. Eur Respir J 2004; 23: 369-372. 
15 Turner DJ, Stick SM, Lesouef KL, Sly PD, Lesouef PN. A new technique to generate and assess forced expiration from raised lung volume in infants. Am J Respir Crit Care Med 1995; 151: 1441-1450.

16 Hall GL, Hantos Z, Petak F, et al. Airway and respiratory tissue mechanics in normal infants. Am J Respir Crit Care Med 2000; 162: 1397-1402.

17 Chambers DC, Tunnicliffe WS, Ayres JG. Acute inhalation of cigarette smoke increases lower respiratory tract nitric oxide concentrations. Thorax 1998; 53: 677-679.

18 Hoyt JC, Robbins RA, Habib M, et al. Cigarette smoke decreases inducible nitric oxide synthase in lung epithelial cells. Exp Lung Res 2003; 29: 17-28.

19 Warke TJ, Mairs V, Fitch PS, Ennis M, Shields MD. Possible association between passive smoking and lower exhaled nitric oxide in asthmatic children. Arch Environ Health 2003; 58: 613-616.

20 Coultas DB, Samet JM, McCarthy JF, Spengler JD. Variability of measures of exposure to environmental tobacco smoke in the home. Am Rev Respir Dis 1990; 142: 602-606.
21 Le Souef PN, Reese AC, Landau LI, James IR. Effect of age on urinary cotinine level in young children. Eur Respir J 1992; 5: Suppl. 15, 106s.

22 Kulig M, Luck W, Lau S, et al. Effect of pre- and postnatal tobacco smoke exposure on specific sensitization to food and inhalant allergens during the first 3 years of life. Multicenter Allergy Study Group, Germany. Allergy 1999; 54: 220-228.

23 Lindfors A, van Hage-Hamsten M, Rietz H, Wickman M, Nordvall SL. Influence of interaction of environmental risk factors and sensitization in young asthmatic children. $J$ Allergy Clin Immunol 1999; 104: 755-762.

24 Halonen M, Stern D, Lyle S, Wright A, Taussig L, Martinez FD. Relationship of total serum IgE levels in cord and 9-month sera of infants. Clin Exp Allergy 1991; 21: 235-241.

25 Blackburn CM, Bonas S, Spencer NJ, Coe CJ, Dolan A, Moy R. Parental smoking and passive smoking in infants: fathers matter too. Health Ed Res 2005; 20: 185-194.

26 Franklin P, Turner S, Mutch R, Stick S. Measuring exhaled nitric oxide in infants during tidal breathing: methodological issues. Pediatr Pulmonol 2004; 37: 24-30. 